\title{
Copper vapor laser machining of polyimide and polymethylmethacrylate in atmospheric pressure air
}

\author{
P. L. G. Ventzek, R. M. Gilgenbach, C. H. Ching, R. A. Lindley, and W. B. McColl \\ Intense Energy Beam Interaction Laboratory, Nuclear Engineering. Department, The University \\ of Michigan, Ann Arbor, Michigan 48109-2104
}

(Received 30 April 1992; accepted for publication 5 June 1992)

\begin{abstract}
A repetitively pulsed copper vapor laser (510 and $578 \mathrm{~nm}$ ) is used to machine an opaque polymer (polyimide-Vespel) and a transparent polymer (polymethylmethacrylate-Lucite). Lucite is machinable by coating the surface with an ink which is semi-opaque to the green and yellow laser light. The repetition rate of the laser was $10 \mathrm{kHz}$ with approximately $0.35 \mathrm{~mJ} / \mathrm{pulse}$ and $3.5 \mathrm{~W}$ average power at the copper vapor laser wavelengths for a pulse width of $40 \mathrm{~ns}$. The copper vapor laser thermally loads the target, generating thermal waves and sound waves in the gas which are investigated using $\mathrm{HeNe}$ laser beam deflection. The gas adjacent to the target is heated to steady state on the order of $100-400 \mathrm{~s}$. Above the etching threshold, at approximately $10 \mathrm{~mJ} / \mathrm{cm}^{2} /$ pulse, the target is rapidly machined: $2-\mathrm{mm}$-diam, $2-\mathrm{mm}$-deep holes are drilled in $300 \mathrm{~s}$ in Vespel. At higher fiuences of $100-150 \mathrm{~mJ} / \mathrm{cm}^{2} /$ pulse in 760 Torr of air it takes $180 \mathrm{~s}$ to bore through a 2-mm-thick disk of Vespel. The machined surfaces of the two polymers are very different. Machined Vespel samples are charred and cratered, whereas the Lucite samples show evidence of melting with little charring. The machining of polymers by visible-light copper vapor lasers is being compared to UV photoablation by $\mathrm{KrF}$ excimer laser light in order to study thermal versus nonthermal etching mechanisms.
\end{abstract}

\section{INTRODUCTION}

Pulsed and cw laser light from the far UV to the infrared has important applications in micromachining materials for electronics applications. ${ }^{1}$ Clean trenches of widths on the order of $0.5-1 \mu \mathrm{m}$ in diameter have been etched in PMMA (polymethylmethacrylate) photoresist with pulsed $193 \mathrm{~nm}$ radiation. ${ }^{2}$ Vias with diameters of less than $5 \mu \mathrm{m}$ in polyimide have been machined with $\mathrm{cw} 257$ $\mathrm{nm}$ radiation. ${ }^{3} \mathrm{CO}_{2}$ and excimer laser light has been compared for the ablation of polystyrene ${ }^{4}$ and the action of pulsed visible $532 \mathrm{~nm}$ laser light on polymers has been investigated using fast imaging techniques. ${ }^{5}$ In previous investigations for micromachining applications, the average power of the laser beam is either low for $\mathrm{cw}$ machining (e.g., $1.2-12 \mathrm{~mW})^{3}$ or the per-pulse beam energy is high (typically $100 \mathrm{~mJ}-1 \mathrm{~J}$ for excimer laser machining). In this article we report the first investigation of the machining process on polymers by a high average-power, commercially available repetitively pulsed visible laser, a copper vapor laser. Although its per-pulse energy is very low (approximately $0.35 \mathrm{~mJ}$ ), the repetition rate is very high (10 $\mathrm{kHz}$ ) giving an average laser power of $3.5 \mathrm{~W}$. It is shown that the machining is a result of thermal degradation of the target as opposed to a photoablative mechanism. $\mathrm{HeNe}$ laser beam deflection ${ }^{6}$ is used as a diagnostic illustrating the effects of machining on the background gas.

\section{EXPERIMENTAL CONFIGURATION}

Samples are machined in atmospheric air with a copper vapor laser (Oxford Laser Company) operating at 510 and $578 \mathrm{~nm}$ wavelengths with a repetition rate of $10 \mathrm{kHz}$ and an approximate per-pulse power of $0.35 \mathrm{~mJ}$ for an average power of $3.5 \mathrm{~W}$. Average powers are measured using a Coherent LM-100XL/LME power meter. The copper vapor laser beam is passed through a focusing lens and is incident normal to the target surface. Target surfaces are always vertical. The target-lens separation is varied so that fluences from $0.35 \mathrm{~mJ} / \mathrm{cm}^{2} /$ pulse to $150 \mathrm{~mJ} / \mathrm{cm}^{2} /$ pulse are obtained. This corresponds to peak average powers of 1.5 $\mathrm{kW} / \mathrm{cm}^{2}$. Many materials are investigated including aluminum, alumina, polyimide (Vespel), and polymethylmethacrylate (Lucite). Helium-neon laser beam deflection is performed by passing a $\mathrm{HeNe}$ laser beam parallel to the sample surface being machined and measuring the deflection of that laser beam on a fast position sensitive detector ${ }^{6}$ with a rise time of $25 \mathrm{~ns}$. The target-detector separation is varied up to $90 \mathrm{~cm}$. Laser beam deflection signals are collected on a fast oscilloscope or (Heath-Schlumberger SR204) strip chart recorder with speeds of up to 10 in. per min. Targets are machined either with a clean unaltered surface or after coating the surface with ink. Two types of ink are used: propynol based solvent yellow 143 (Color Index 143) and propynol based solvent blue 70 (Color Index 70), ${ }^{7,8}$ Other color inks were also tested.

\section{EXPERIMENTAL RESULTS AND DISCUSSION}

Opaque materials with degradation temperatures less than $300^{\circ} \mathrm{C}$ were readily machined. An example of such a material is polyimide in the bulk form of SP-1 Vespel. Vespel does not melt or have a glass transition temperature but begins to degrade due to oxidation in the range of $300^{\circ} \mathrm{C} .9$ Materials such as Lucite that are transparent to the visible copper vapor laser light were not machinable even with well focused laser light. Lucite begins to distort between 60 and $93{ }^{\circ} \mathrm{C}^{10,11}$ and its maximum temperature for continued heat resistance is $50^{\circ} \mathrm{C}$ compared to $260^{\circ} \mathrm{C}$ 

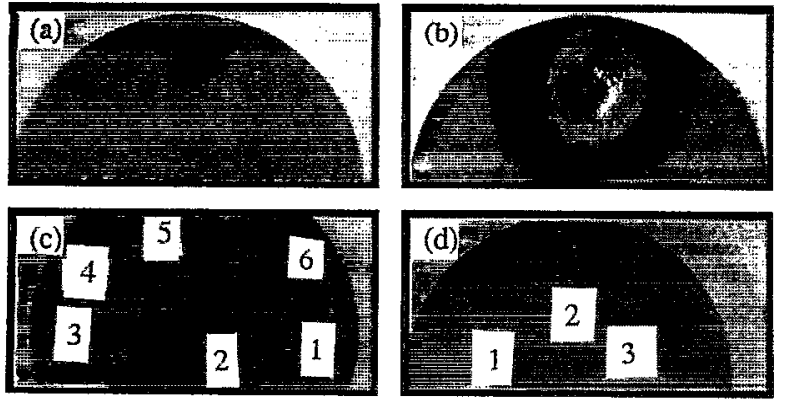

L 」

$1 \mathrm{~cm}$

FIG. 1. Machined polyimide (Vespel) samples: (a) machined with copper vapor laser ( $50 \mathrm{~mJ} / \mathrm{cm}^{2} /$ pulse); (b) machined with $\mathrm{KrF}$ excimer laser, 14-20 J/ $\mathrm{cm}^{2}, 150$ pulses in air; (c) Vespel machined at $17 \mathrm{~mJ} / \mathrm{cm}^{2}$ / pulse for different exposure times $(1=10 \mathrm{~s}, 2=30 \mathrm{~s}, 3=60 \mathrm{~s}, 4=90 \mathrm{~s}$, $5=120 \mathrm{~s}, 6=180 \mathrm{~s}$ ); (d) Vespel machined with different intensities of copper vapor laser light $\left(1=100 \mathrm{~mJ} / \mathrm{cm}^{2} /\right.$ pulse, 2 and $3=10 \mathrm{~mJ} / \mathrm{cm}^{2}$ / pulse).

for polyimides. ${ }^{10,11}$ Opaque materials with high thermal conductivities and high melting or decomposition temperatures such as aluminum and alumina were also not machinable even with well-focused laser beams (up to 150 $\mathrm{mJ} / \mathrm{cm}^{2} /$ pulse).

In order to compare thermal versus nonthermal ablative machining, a typical copper vapor laser machined polyimide sample [Fig. 1(a)] and a KrF excimer laser ablated polyimide sample [Fig. 1(b)], both processed in atmospheric air, are shown in Fig. 1. The ablated surface of the $\mathrm{KrF}$ laser ablated target is clean and free of any evidence of melting or burning. Around the ablation target is evidence of soot and other debris deposited by the explosive emission of the ablated material from the Vespel surface. The mechanism of debris production has been recently investigated by Kuper and Brannon. ${ }^{12}$ It is important to note that the process of excimer laser removal of material from the Vespel surface is a single pulse event and the mechanism of material removal is termed ablative photodecomposition. ${ }^{1,13}$ In contrast, the surface of the copper vapor laser-machined sample [Figs. 1(a), 1(c), and $1(d)]$ is blackened, charred, and shows cratering. At low fluences when no machining occurs, the target is discolored to a lighter brown than the dark brown of the unaltered Vespel surface. Figure 1(c) shows the machining process for several different exposure times for Vespel machined with approximately $17 \mathrm{~mJ} / \mathrm{cm}^{2} /$ pulse. After $10 \mathrm{~s}$ (hole labeled 1), the surface appears swelled but is distinctly blackened; after $30 \mathrm{~s}$, however (hole labeled 2), the machined surface is depressed below the unmachined surface. By $180 \mathrm{~s}$ (hole labeled 6) a cone is machined deep into the sample with 5 or 6 cracks in evidence at the wall of the sample. This cone is characteristic of those observed ${ }^{3}$ for cw UV ablation of polyimide. Figure 1(d) shows Vespel machined with different intensities of copper vapor laser light. Hole 1 was drilled with a fluence of $100 \mathrm{~mJ} / \mathrm{cm}^{2} /$ pulse. Note that the hole is much narrower than the holes (2 and 3) machined with a fluence of $10 \mathrm{~mJ} / \mathrm{cm}^{2} /$ pulse. A typical time to bore through a 2-mm-thick Vespel target

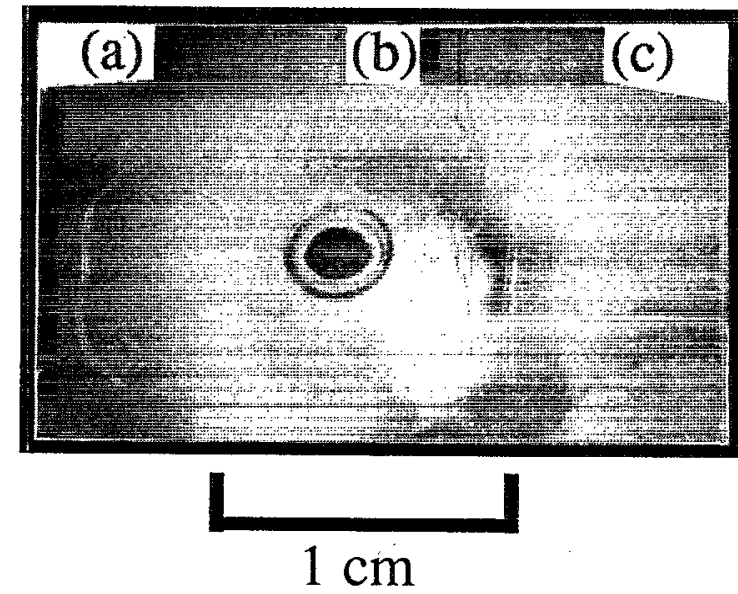

FIG. 2. Machined polymethylmethacrylate (Lucite) sample: (a) no surface treatment, (b) CI blue 70 ink on surface before machining, (c) CI yellow 143 ink on surface before machining. Fluence $=33 \mathrm{~mJ} / \mathrm{cm}^{2} /$ pulse. The sample was irradiated for $3 \mathrm{~min}$ at $10 \mathrm{kHz}$. The white spot by (b) is a light reflection from the light used to photograph the sample.

was $180 \mathrm{~s}$ for $100 \mathrm{~mJ} / \mathrm{cm}^{2} /$ pulse and $300 \mathrm{~s}$ for $10 \mathrm{~mJ} / \mathrm{cm}^{2} /$ pulse. The former corresponds to an average of $1 \mathrm{~nm}$ per pulse or $10 \mu \mathrm{m} / \mathrm{s}$ machining speed at that fluence.

Lucite (or polymethylmethacrylate), despite being a material that is transparent to visible copper vapor laser light and is not machinable even with strongly focused beams, can be machined by coating with an ink which is semi-opaque to the green and yellow light. Similar techniques have been applied by Srinivasan et al. who doped PMMA with UV absorbing species to enhance the etch rate for excimer laser light. ${ }^{14,15}$ A Lucite target machined with different types of ink surface preparation is presented in Fig. 2. Figure 2(a) is a Lucite surface which had 33 $\mathrm{mJ} / \mathrm{cm}^{2} /$ pulse copper vapor laser light incident on it with no surface treatment. No damage to the surface is evidenced. Figure 2(b) is a machined surface that was coated with $\mathrm{CI}$ Blue 70 ink. The machined surface is clear and shows evidence of melting around the edges of the machined pit.

In the case of Lucite, it appears that the ink absorbs enough of the laser light to locally heat the Lucite surface causing it to melt and vaporize. Lucite begins to melt ${ }^{16}$ at $160^{\circ} \mathrm{C}$ and ignites at $338^{\circ} \mathrm{C}$. It is likely that the large quantity of particulate generated is recondensed vapor. The thin liquid surface is more absorbent than the solid, causing the melting and vaporization process to continue. When the surface area on the walls of the pit becomes too large, the effective laser fluence drops, providing too low of an energy density to maintain the melting process, and thus machining ceases. The walls of the crater resolidify and the pit becomes transparent again.

Figure 2(c) is the copper vapor laser light-irradiated surface which has been coated with CI 143 solvent yellow. In this case, there appears to have been little damage to the polymer surface except for possibly some melting of the ink itself. The melt pool of the ink does not appear to have 


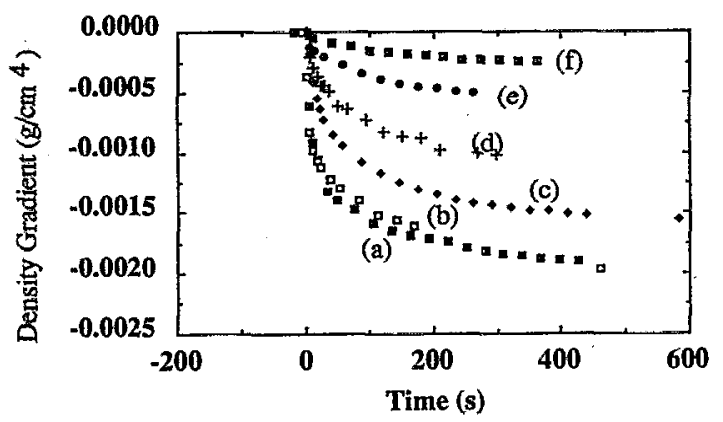

FIG. 3. Thermal deflection signals digitized from original strip-chart recorder data for various HeNe probe beam displacements normal to the polyimide target surface: (a) $0.5 \mathrm{~mm}$, (b) $1 \mathrm{~mm}$, (c) $1.5 \mathrm{~mm}$, (d) $2 \mathrm{~mm}$, (c) $3 \mathrm{~mm}$, (f) $3.85 \mathrm{~mm}$. Fluence $=0.35 \mathrm{~mJ} / \mathrm{cm}^{2} /$ pulse.

been hot enough for the Lucite to be melted and no machining was achieved.

The physical appearance of the machined polyimide and polymethylmethacrylate suggests that the machining process is that of thermal degradation of the polymer. Polymers fall into one of two classes based on the composition of the material into which they degrade upon exposure to heat. One class is composed of those polymers that degrade almost entirely into their monomer unit or low molecular weight liquid or gas state molecules. The other class (typically containing aromatic groups in the monomer) is composed of those whose initial degradation products interreact forming carbonized products, other sorts of macromolecules, or what can be classified as coke (nonvolatile residue). ${ }^{17,18}$ An example of the type of polymer that degrades into its monomer unit or low molecular weight volatiles with little or no coke residue is PMMA (Lucite); an example of the class that degrades largely to coke is polyimide (Vespel). Consistent with thermal degradation, the appearance of the machined craters for $\mathrm{Lu}$ cite are clear with little or no charring or residue in evidence while the craters in Vespel are blackened.

The machining site for Lucite shows no luminous plume, whereas the site for Vespel shows a red then yellowish luminous plume while machining is proceeding, suggesting that the machining process is exothermic. Thermal degradation of a polymer to coke is highly exothermic but the degradation process for materials such as PMMA is not highly exothermic. ${ }^{17}$

When the repetitively pulsed copper vapor laser light irradiates the surface, two effects are observable with the HeNe laser beam deflection technique. ${ }^{6,19,20}$ The pulsed heating and removal of material from the surface drives sound waves into the background gas; the background gas is additionally heated by conduction from the sample which is being thermally loaded by the $3.5 \mathrm{~W}$ of laser light:

Figure 3 shows thermal deflection signals for the case of simple surface heating at a fluence of $0.35 \mathrm{~mJ} / \mathrm{cm}^{2}$ / pulse. The rise time of the thermal deflection signals corresponds to the diffusion time for the solid polyimide sample. The thermal diffusivity of Vespel ${ }^{9}$ is $2.3 \times 10^{-3} \mathrm{~cm}^{2} / \mathrm{s}$. The length and diameter of the Vespel cylinders that were heated are 2.54 and $1.9 \mathrm{~cm}$, respectively. An average of the two numbers provides an approximate scale length for the sample. The diffusion time ${ }^{19}$ can be defined as:

$$
\tau_{\text {difusion }}=x^{2} /\left(4 D_{\text {Vespel }}\right),
$$

where $\tau_{\text {diffusion }}$ is the diffusion time, $x$ is the sample scale length, and $D_{\text {Vespel }}$ is the thermal diffusion coefficient. The diffusion time for the solid is $535 \mathrm{~s}$. The diffusion time for thermal transport through the air to the probe is very fast. For a probe beam located $0.3 \mathrm{~cm}$ from the surface and a thermal diffusivity of air of $0.22 \mathrm{~cm}^{2} / \mathrm{s}$, the theoretical thermal diffusion time is $100 \mathrm{~ms}$ for the gas. It is apparent from Fig. 3 that the time for the laser deflection signals to saturate (an estimate of the diffusion time) is between 200 and $400 \mathrm{~s}$ which is in general agreement with this simple diffusion calculation. It is interesting to note that the thermal laser deflection signal in single-pulsed excimer laser ablation experiments scales with the thermal diffusivity of the background gas instead of the solid. ${ }^{19}$

The thermal deflection signal data in Fig. 3 can also be used to estimate the rate of heat transfer from the surface in the direction normal to the target and a gas temperature adjacent to the surface. The density gradients at $300 \mathrm{~s}$ after the initiation of surface heating were plotted as a function of distance from the target surface. From this data an estimation of the density change from ambient can be calculated. Assuming pressure equilibrium, the near-surface temperature profile can also be calculated. For the case of surface heating the surface temperature is approximately $200^{\circ} \mathrm{C}$. The heat flow from the surface was estimated to be $0.15 \mathrm{~W} / \mathrm{cm}^{2}$ for a loading of $3.5 \mathrm{~W}$ for a fluence of 0.35 $\mathrm{mJ} / \mathrm{cm}^{2} /$ pulse.

Photoacoustic measurements for a HeNe probe beam 2 $\mathrm{mm}$ from the polyimide surface for a fluence of $17 \mathrm{~mJ} /$ $\mathrm{cm}^{2} /$ pulse are presented in Fig. 4. Both traces are acquired on a fast digital signal analyzer and are averages over 32 copper vapor laser shots. Very weak photoacoustic pulses are sent from the surface. The amplitude of these pulses decreases with machining time as does the time it takes for the pulse to reach the probe beam. The well defined nature of the sound pulse at less than $100 \mathrm{~s}$ [Fig. 4(a)] after the initiation of machining is probably symptomatic of the flatness of the machined surface at early times. As the surface is machined, the bore hole becomes more conical. The sound pulse therefore originates from sources at a variety of depths from the surface, deforming the pulse and increasing its traveling time to the HeNe probe [Fig. 4(b)]. Previously, sound pulses combined with the probe beam deffection technique have been used to measure the depths of etch pits from $\mathrm{KrF}$ laser ablation ${ }^{20}$ and weak deflections of rotating rods. ${ }^{21}$ The delay of the sound pulse cannot be directly correlated to an etch depth while performing repetitively pulsed machining because the gas adjacent to the machined surface is being heated while the machining is taking place and a natural convective flow is occurring.

After $10 \mathrm{~min}$ of irradiating the Vespel surface the $\mathrm{HeNe}$ probe beam was translated various distances from the surface to gain information about the velocity of the disturbance. It was found that the velocity was $572 \mathrm{~m} / \mathrm{s}$ 

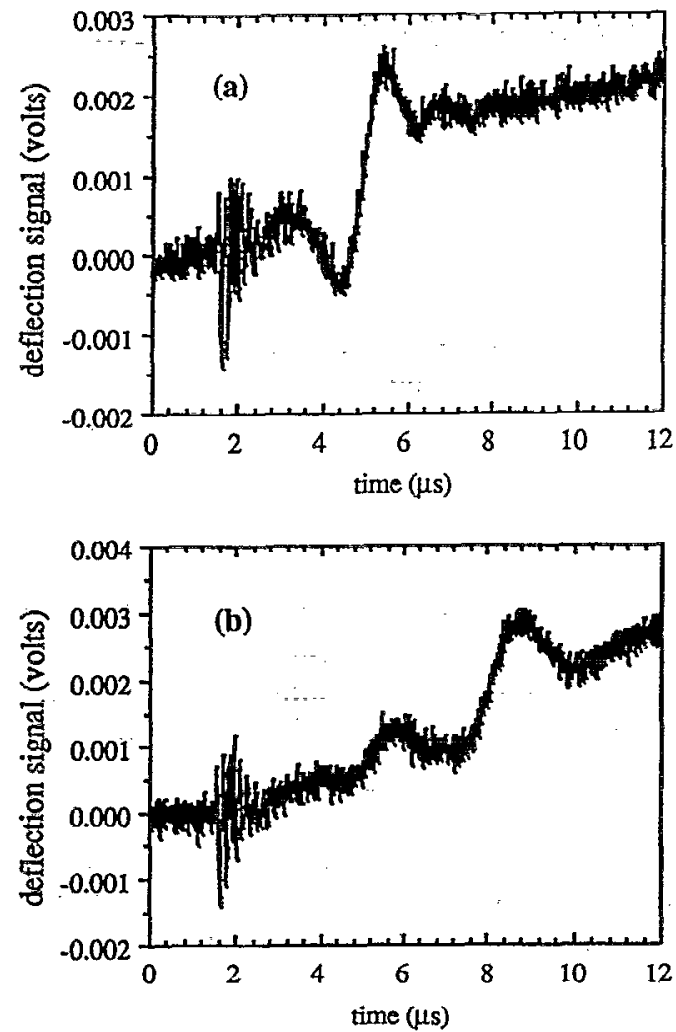

FIG. 4. Sound pulses traveling from surface (probe beam at $0.5 \mathrm{~mm}$ ): (a) $55 \mathrm{~s}$, (b) $464 \mathrm{~s}$ after the initiation of machining with $17 \mathrm{~mJ} / \mathrm{cm}^{2} / \mathrm{puise}$.

and constant over a distance of $3 \mathrm{~mm}$ from the surface. Assuming that the increase in the sound velocity was due to the heating of the gas through which the pulse traveled, an average near-surface temperature of $530^{\circ} \mathrm{C}$ can be estimated which is above the temperature where degradation is expected to be observed. ${ }^{9}$

\section{CONCLUSION}

Polyimide (Vespel) and PMMA (Lucite) targets are readily machinable using copper vapor lasers. Materials such as Lucite that are transparent to the visible copper vapor laser light are machinable by coating the surface with an ink that absorbs the green and yellow laser light.
The physical appearance of the machined holes in the samples suggests that thermal degradation of the polymer is responsible for their features. Laser beam deflection measurements show that machining results in the generation of two hydrodynamic effects in the adjacent air background: sound/shock waves and thermal waves. The thermal wave behavior is observed to scale with the thermal diffusivity of the solid.

\section{ACKNOWLEDGMENTS}

This research is supported by the National Science Foundation (CTS-9108971) and the Department of Energy. RAL has a DOE Magnetic Fusion Energy Technology fellowship. The authors acknowledge the technical assistance of D. Love and A. Allen.

${ }^{1}$ J. T. C. Yeh, J. Vac. Sci. Technol. A 4, 653 (1986).

${ }^{2}$ R. A. Lawes, Appl. Surf. Sci. 36, 485 (1989).

${ }^{3}$ G. V. Treyz, R. Scarmozzino, and R. M. Osgood, Jr., Appl. Phys. Lett. 55, 346 (1989).

${ }^{4}$ W. W. Duley and G. Allan, Appl. Phys. Lett. 55, 1701 (1989).

${ }^{5}$ T. Zyung, H. Kim, J. C. Postlewaite, and D. D. Dlott, J. Appl. Phys. 65, 4548 (1989).

${ }^{6}$ C. L. Enloe, R. M. Gilgenbach, and J. S. Meachum, Rev. Sci. Instrum. 58, 1597 (1987).

${ }^{7}$ Society of Dyers and Colourists, Eds. Colour Index, 3rd ed. (Society of Dyers and Colourists, Bradford, UK, 1971).

${ }^{8}$ Inks prepared by Formulabs, P. O. Box 1056, Escondido, CA 92025 4037.

${ }^{9}$ Manufacturer data, The Properties of DuPont VESPEL Parts, DuPont, E-26800, REV1-88.

${ }^{10} \mathrm{~J}$. A. Dean, Ed., Lange's Handbook of Chemistry, 13th ed. (McGrawHill, New York, 1985).

${ }^{11}$ C. T. Lynch, Ed., CRC Handbook of Materials Science (CRC, Cleveland, OH, 1975), Vol. III.

${ }^{12}$ S. Kuper and J. Brannon, Appl. Phys. Lett. 60, 1633 (1992).

${ }^{13}$ R. Sauerbrey and G. H. Pettit, Appl. Phys. Lett. 55, 421 (1989).

${ }^{14}$ R. Srinivasan, B. Braren, R. W. Dreyfus, L. Hadel, and D. E. Seegar, J. Opt. Soc. Am. B 3, 785 (1986).

${ }^{15}$ R. Srinivasan and B. Braren, Appl. Phys. A 45, 289 (1988).

${ }^{16}$ C. A. Daniels, Polymers: Structure and Properties (Technomic Publishing, Lancaster PA, 1989).

${ }^{17}$ R. M. Aseeva and G. E. Zaikov, in "Advances in Polymer Science" Key Polymers: Properties and Performance (Springer, New York, 1985), Vol. 70, p. 171 .

${ }^{18}$ N. Grassie, in "High Polymers", Chemical Reactions of Polymers, edited by E. M. Fettes (Interscience, New York, 1964), Vol. XIX, p. 565.

${ }^{19}$ J. A. Sell, D. M. Heffelfinger, P. L. G. Ventzek, and R. M. Gilgenbach, J. Appl. Phys. 69, 1330 (1991).

${ }^{20}$ P. L. G. Ventzek, R. M. Gilgenbach, D. M. Heffelfinger, and J. A. Sell, J. Appl. Phys. 70, 587 (1991).

${ }^{21}$ J. A. Sell, Rev. Sci. Instrum. 63, 3583 (1992). 